\title{
La tentación del diario: escritura de la intimidad y experiencia ética en La tentación del fracaso de Julio Ramón Ribeyro
}

The temptation of the diary: writing about intimacy and the ethical experience in La tentación del fracaso by Julio Ramón Ribeyro

A tentação do diário: escritura da intimidade e experiência ética em La tentación del fracaso de Julio Ramón Ribeyro

\section{Alberto Giordano}

UNIVERSIDAD NACIONAL DE ROSARIO/CONICET, ARGENTINA

Profesor Titular de la Facultad de Humanidades y Artes de la Universidad

Nacional de Rosario y Doctor en Letras de la Universidad de Buenos

Aires. Entre sus últimas publicaciones se encuentran: La contraseña

de los solitarios. Diarios de escritores (Beatriz Viterbo Editora, 2012),

Vida y obra. Otra vuelta al giro autobiográfico (Beatriz Viterbo

Editora, 2010), El giro autobiográfico de la literatura argentina

actual (Mansalva, 2008), Una posibilidad de vida. Escrituras íntimas

(Beatriz Viterbo Editora, 2006), Modos del ensayo. De Borges a Piglia.

Segunda edición corregida y aumentada (Beatriz Viterbo Editora, 2005). Correo electrónico: albertogiordano59@gmail.com

\footnotetext{
Artículo de reflexión

El presente artículo corresponde a un proyecto de investigación concluido sobre "Autofiguración y experiencia en diarios de escritores", financiado por el Consejo Nacional de Investigaciones Científicas y Técnicas (CONICET), Argentina.

Documento accesible en línea desde la siguiente dirección: http://revistas.javeriana.edu.co 


\section{Resumen}

Este trabajo propone una lectura de La tentación del fracaso, el diario personal de Julio Ramón Ribeyro, atenta al espesor literario que cobra en él la escritura de la intimidad y a la intensidad de las experiencias éticas que lo atraviesan. Dichas experiencias remiten a una subjetividad escindida y tensionada entre deseos heterogéneos, tensión que cristaliza en la figuración del diarista como personaje novelesco. $\mathrm{Al}$ mismo tiempo, se examinan las diferentes alternativas del insistente proceso de deliberación que recorre La tentación del fracaso, en el que se discute el valor y la eficacia de llevar un diario y las posibilidades de que esta escritura íntima se convierta en obra literaria.

Palabras clave: Julio Ramón Ribeyro; La tentación de fracaso; escritura de la intimidad; experiencia ética

\section{Abstract}

This work proposes a reading of La tentación del fracaso, Julio Ramón Ribeyro's journal, which is focused on the literary importance that gain the intimate writing and the intensity of the ethical experiences that run through it. Such experiences refer to a subjectivity both stressed and split among heterogeneous desires, a tension that is crystallized in the figuration of the journalist as a fictional character. At the same time, we examine the insistent deliberation process that runs through La tentación del fracaso, in which the value and effectiveness of carrying a journal and the chances of this intimate writing to become a literary work are discussed.

Keywords: Julio Ramón Ribeyro; La tentación del fracaso; intimate writing; ethical experience

\section{Resumo}

Este trabalho propõe uma leitura de La tentación del fracaso, o diário pessoal de Julio Ramón Ribeyro, atenta à espessura literária que cobra nele a escritura da intimidade $\mathrm{e}$ à intensidade das experiências éticas que o atravessam. Tais experiências remetem a uma subjetividade cindida e tensionada entre desejos heterogêneos, tensão que se cristaliza na figuração do autor do diário como personagem novelesco. Ao mesmo tempo, se examinam as diferentes alternativas do insistente processo de deliberação a que recorre La tentación del fracaso, onde se discute o valor e a eficácia de construir um diário e as possibilidades de que esta escritura íntima se converta em obra literária.

Palavras-chave: Julio Ramón Ribeyro; La tentación de fracaso; escritura da intimidade; experiência ética

RECIBIDO: 12 DE MAYO DE 2014 EVALUADO: 10 DE JUNIO DE 2014. DISPONIBLE EN LÍNEA: 15 DE ENERO DE 2015

\section{Cómo citar este artículo:}

Giordano, Alberto. "La tentación del diario: escritura de la intimidad y experiencia ética en La tentación del fracaso de Julio Ramón Ribeyro". Cuadernos de Literatura 19.37 (2015): 341-360. doi:10.11144/Javeriana.CL19-37.ltde 
EN LA ENTRADA del 22 de abril de 1978, a sus cuarenta y siete años (la referencia a la edad no es un dato accesorio, ya que alude a un momento crucial de la vida del escritor en el que se le impone la idea de que su obra, de algún modo, está cumplida, que lo que quedará de ella, si es que algo queda, ya fue escrito), Julio Ramón Ribeyro anota en su diario que estuvo releyendo Prosas apátridas y que le parece lo mejor que dio de sí mismo. La sorpresa y la emoción frente a hallazgos que no recordaba cristalizan en un juicio que trasciende lo estético en la dirección del énfasis moral: "son textos que me sobrepasan, quiero decir que son mejores que yo" (La tentación del fracaso 611). ${ }^{1}$ Seguramente no habrá sido ajena a esta valoración la noticia tan halagüeña, recibida unos meses antes en su departamento parisino, de que en Perú muchos jóvenes frecuentaban y discutían el libro con admiración porque encontraban en los fragmentos reunidos en él un punto de vista penetrante y sin concesiones, perfilado por el escepticismo y la ironía, sobre los meandros y las costumbres del alma que se resiste a las supersticiones de la vida en sociedad o que cae vencida bajo su influjo.

Aunque Ribeyro establece en la "Nota del autor" que antecede al libro la filiación entre ese conjunto de textos sin territorio literario propio, en el que coexisten apuntes circunstanciales, reflexiones más o menos elaboradas y la narración de anécdotas, con Le spleen de Paris de Baudelaire, el impulso que los orienta es tanto poético como moral, en la tradición francesa del estudio psicológico y la crítica elegante e impiadosa a la hipocresía y la corrupción espiritual de los contemporáneos. Esa tradición espléndida, con la que el escritor peruano se apasionó en la adolescencia, usufructuando de la biblioteca familiar, arranca en el siglo XVI con Montaigne, el precursor de la filosofía del honnête homme, y alcanza cimas extraordinarias de sutileza e ingenio en los siglos posteriores con La Rochefoucauld y La Bruyère, con Montesquieu y Voltaire. ${ }^{2}$ Como vástago de esta tradición admirable, Ribeyro se reconoce mejor que sí mismo en el acabado formal y la tensión espiritual de sus Prosas apátridas porque en ellas encarna, como autor, la figura inquietante del escéptico que se somete activamente al ejercicio de la duda radical y gana en intensidad retórica y estética lo que sacrifica en comodidad doctrinaria. ${ }^{3}$

1 Ribeyro aclara que estuvo releyendo tanto la primera edición de Tusquets (1975), que consta de 85 textos, como la edición ampliada que en esos momentos preparaba la Editorial Milla Batres en Lima (1978), en la que se agregaron 61 textos más. Posteriormente, en 1986, Tusquets publicó las Prosas apátridas completas, con un total de 200 textos.

2 El lego puede aproximarse a la riqueza de esta tradición a través de un estudio de Agustín Yáñez (1961) que combina de manera magistral exposición informativa con interpretación penetrante.

3 La posición del escéptico es inquietante para el propio Ribeyro porque la duda sistemática, según registra en otra entrada del diario también a propósito de Prosas apátridas, puede caer en 
En un ensayo luminoso que revela sus tempranas dotes para la crítica literaria (esas que en la juventud lo hacían dudar de sus aptitudes para el trabajo creador), ${ }^{4}$ Ribeyro celebra la inteligencia y la sensibilidad extraordinarias de Ernest Robert Curtius en ocasión de su muerte, y a propósito del admirable Essai sur la France, subraya los valores fundamentales de la cultura literaria francesa con los que se identifica, lo mismo que el estudioso alemán, sin reservas: el gusto innato por el escepticismo, la creencia en que las obras sirven como documentos para el conocimiento del hombre y la eficacia del trabajo con formas sintácticas cristalizadas. Según Curtius, principalmente a través de la obra de los moralistas, la prosa francesa ha "acumulado en sus máximas y aforismos un material incomparable para el estudio del corazón humano" (Ribeyro, La caza sutil 37). Sin caer en los excesos que abruman al lector de los Dichos de Luder, ${ }^{5}$ las Prosas apátridas avanzan resueltamente en esta dirección de un humanismo crítico formalizado según patrones clásicos. Cuando Ribeyro afirma que este no es sólo su mejor libro, sino que es un libro mejor que quien lo escribió, reconoce, como ya señalamos, que el conjunto de los fragmentos impone la figura de un autor definida en buena medida a imagen y semejanza de la de sus admirados moralistas franceses, un escéptico fortalecido por la serena aceptación de que la única certidumbre que se puede adquirir mientras se vive intensamente es que no hay certezas, que la vida es un juego misterioso, inexplicable, del que se desconocen las reglas. Aunque despierta admiración y simpatía, la figura resulta un poco distante, sin el espesor novelesco que los lectores persiguen incluso en los libros misceláneos (el que podrían encontrar, por ejemplo, en el diario del autor), porque brilla demasiado idéntica a sí misma, sostenida como está en una posición moral claramente

la esterilidad y propiciar la dejadez y el abandono (ver la entrada del 21 de marzo de 1974; 407). Reparar en este tipo de ambigüedades que desestabilizan y enriquecen las autofiguraciones del escritor cuando expone su intimidad es uno de los propósitos de este trabajo.

4 "11 de noviembre [de 1955] (...) Debo ahora plantearme esa pregunta que siempre he temido porque me parece que en su formulación existe ya el reconocimiento implícito de un fracaso: ¿Seré yo más bien un crítico? ¿Se estará operando en mi conciencia o se habrá operado ya subterráneamente el tránsito del poeta al analista? (...) Ser un mal creador sería para mí mucho más estimable que ser un buen crítico" (88). En Prosas apátridas y en el diario, Ribeyro diferencia claramente el trabajo del crítico, cuyos medios son los conceptos y su propósito la búsqueda de la verdad, de la experiencia creadora, a la que juzga superior porque inventa formas que pueden resultar perdurables (ver Prosas apátridas 102).

5 Se trata del libro fragmentario más radical de Ribeyro y el menos amable: la apuesta excluyente al golpe de efecto sostenido en una apreciación ingeniosa y sintética (cada dicho no tiene, por lo general, más que un par de líneas) condiciona en exceso la respuesta del lector. Dichos de Luder se publicó en 1989 en Lima (Jaime Campodónico Editor), y se encuentra reproducido en: http://leda.spaceports.com/ bioxid/luder/luder.html, de donde lo consultamos. 
definida - corrosiva pero inmutable - y en el ejercicio de un estilo que, como el de algunos prosistas franceses del siglo XIX que integran su panteón personal (Constant, Flaubert y Baudelaire), tiende a lo "metálico" e "incorruptible" (Ribeyro, Diario personal 286). La conjunción del deseo de resultar penetrante y una escritura transparente, inclinada a lo geométrico, instala a veces divergencias entre el decir y lo dicho en las que se revela cierta fijeza de la posición enunciativa. Así en el fragmento 23, el elogio de la inmadurez como destino de lo humano, en los pasos de Gombrowicz, lo formaliza el recurso a la máxima con desarrollo reflexivo, uno de los expedientes retóricos más maduros. ${ }^{6}$

Aunque se trata de una afirmación que el desarrollo de este trabajo querría desplazar ligeramente, se pueden situar en el centro de la obra literaria de Ribeyro las recopilaciones de sus libros de cuentos cortos tituladas La palabra del mundo (como él mismo lo reconocía, cuando observaba el carácter "antiépico" de su escritura narrativa y la incapacidad para desarrollar una trama con densidad polifónica, las novelas quedan relegadas a un distante segundo plano). ${ }^{7}$ La forma paradigmática de estos cuentos, en los que se combina la visión neorrealista con el relato lineal, exento de retórica y análisis, a la manera de Chejov, es la de la crónica mínima pero intensa de historias comunes y desafortunadas, historias de humillaciones y fracasos, protagonizadas por personajes grises o inadaptados. Entre las obras supuestamente marginales, por su extensión (más de seiscientas páginas), su múltiple valor documental (del transcurrir de la vida y los avatares de la obra), pero sobre todo por su riqueza literaria y su complejidad como experiencia ética, la más relevante es el diario personal, que registra entradas de veintiocho años (entre 1950 y 1978) y que el autor tituló, en el momento de publicarlo, La tentación del fracaso. La hipótesis que nos gustaría sostener es que el diario, en su entramado polifónico tan rico y matizado como el de una novela moderna, y en su carácter de experimento existencial, es lo mejor que Ribeyro dio de sí mismo como escritor y moralista, y probablemente la obra por la que perdure como otra cosa que un narrador "menor", o tal vez sería mejor decir, la obra que reformuló los términos en los que hay que apreciar todo lo que puede

6 Ver Prosas apátridas 29.

7 En vida del autor, la Editorial Milla Batres publicó 4 volúmenes de La palabra del mundo que recogían los libros de cuentos publicados por Ribeyro a partir de 1955: Vols. 1 y 2 en 1972; Vol. 3 en 1977 y Vol. 4 en 1992. Con el mismo título, en 2010, la filial española de Seix Barral publicó en un solo volumen de más de mil páginas una edición completa de los cuentos de Ribeyro que incluye varios inéditos y desconocidos. Las tres novelas que el autor consideraba fallidas, aunque las dos primeras ganaron premios de importancia en Perú, son: Crónica de San Gabriel (1960); Los geniecillos dominicales (1965) y Cambio de guardia (1976). 
la condición "menor" de un escritor tentado por el anacronismo, lo inacabado y la pasión por la supervivencia en situaciones límites. El complemento de esta hipótesis sostiene que la potencia literaria y moral del diario presupone los deseos y las experiencias de una subjetividad escindida y tensionada entre impulsos heterogéneos, ni mejor ni peor que la imagen que el autor se hacía de sí mismo, sino más bien diferente y anómala.

Ribeyro comenzó a publicar su diario en 1992, de regreso a Lima después de algo más de tres décadas de residencia en París, cuando ya era un escritor consagrado. Faltaban sólo dos años para su muerte. Como los siguientes, el primer volumen de La tentación del fracaso lo editó Jaime Campodónico y comprende los años que van de 1950 a 1960; son los años de la bohemia en Lima, los comienzos como escritor, el intento fallido de estudiar derecho y los viajes por Europa como becario y buscavidas. El segundo volumen se editó en 1993 y comprende los años de madurez literaria y vital que van de 1960 a 1974, años en los que se establece en París como redactor de la sección latinoamericana de la Agencia France-Presse, contrae matrimonio con Alida Cordero, se convierte en padre, es nombrado Agregado cultural de la embajada de Perú en París y delegado ante la UNESCO (a partir de 1972) y se le declara el cáncer de esófago (en 1973) con el que tendrá que convivir hasta el final, durante dos décadas. La edición del tercer volumen fue póstuma (1995) e incluye sólo tres años, de 1975 a 1978, en los que además de publicar su mejor compilación de relatos (Silvo en el rosedal, de 1977), se prolongan sus experiencias como burócrata, enfermo y padre de familia, y en los que la frecuencia y la intensidad del ejercicio intimista se potencia con resultados notables. En la introducción que acompañó la publicación del primero, ${ }^{8}$ Ribeyro calculaba en diez o doce volúmenes la edición completa del diario - pues nos enteramos de que nunca dejó de llevarlo y que la preminencia y la intensidad que lo autobiográfico había cobrado a partir de los setenta se sostuvo hasta el final-, pero por decisión de los herederos nada se publicó hasta el momento de los cuadernos posteriores a 1978.

En una anticipación sorprendente para un escritor que todavía estaba definiendo el perfil narrativo que iba a identificar su obra, a los veintiocho años, Ribeyro fantasea con la posibilidad de un libro autobiográfico misceláneo que podría convertirse en su aporte más sustancial a la literatura latinoamericana:

8 La nota está reproducida al comienzo de la edición completa de La tentación del fracaso (2003) con la que trabajamos para la escritura de este trabajo. 
3 de agosto [de 1957]

(...)

En realidad - tengo casi la evidencia - si alguna vez escribo un libro importante, será un libro de recuerdos, de evocaciones. Este libro lo compondré no sólo con los fragmentos de mi vida, sino con los fragmentos de mis estilos y de todas mis imposibilidades literarias. Un libro de memorias -en un grado mucho mayor que la novela- es un verdadero cajón de sastre. En él caben las anécdotas, las reflexiones abstractas, el comentario de los hechos, el análisis de los caracteres, etc. (151-152).

En este libro imaginario, que no plantea los problemas de composición con los que tiene que confrontarse el narrador (la elección de un punto de vista novedoso desde el que se puedan apreciar aspectos inusuales de la realidad), pero que estaría lejos de alcanzar intensidad literaria si sólo quedara librado a los azares de la rememoración y no encontrase un principio constructivo inmanente, un principio rítmico que rigiera la alternancia entre insistencias y desvíos y regulase los desplazamientos o los saltos de registros; en un libro parecido a este se convirtió La tentación del fracaso al cabo de los años y, para muchos lectores y algunos críticos, es el auténtico centro de la obra de Ribeyro, su creación más original. Tal como lo imaginaba el joven escritor, es un libro esencialmente fragmentario que consiente las mezclas de estilo y la coexistencia sin mediaciones de registros heterogéneos (en él caben la anécdota circunstancial —autobiográfica o ajena-, el testimonio personal de eventos históricos, esbozos de crítica literaria, la enunciación de principios poéticos, la reflexión moral o filosófica, el examen de conciencia y las perplejidades de la introspección, el retrato espiritual del prójimo, la crítica de las costumbres y la continua digresión sobre distintos aspectos de esa práctica tan curiosa que es llevar un diario personal cuando se es un escritor, es decir, alguien advertido sobre el carácter artificioso de cualquier notación que se pretenda verdadera o sincera). No es un libro de memorias, porque la perspectiva temporal de cada registro es el presente de lo cotidiano, pero sí un memorial de cómo juegan las obsesiones y su contraparte, la aceptación de lo incierto, en el diseño singular de una vida.

La heterogeneidad de registros, todavía más rica que la síntesis propuesta en el párrafo anterior, y la extensión, que presupone vivencias y sucesos que tuvieron lugar a lo largo de casi tres décadas, en edades y contextos diferentes, conspiran contra las posibilidades de ensayar una visión de conjunto de todo lo que pasa por La tentación del fracaso. En un ensayo en que expone sus amplios conocimiento sobre la obra del autor, una lectura ajustada de los distintos 
reenvíos entre la escritura del diario y la de los cuentos y las novelas, y una interpretación atenta de los movimientos del diarista en términos de autofiguración, Susana Zanetti (2006) realizó una lectura lo suficientemente comprensiva del entramado de motivos y procedimientos que densifican la textura del libro como para eximirnos del reto de intentar también nosotros una aproximación con pretensiones totalizadoras. Las notas que siguen abordan sólo algunos aspectos del arte intimista de Ribeyro, pero de los más relevantes a la hora de apreciar los alcances éticos y los hallazgos literarios de su práctica como escritor-diarista.

Para la moral que sostienen algunas estéticas contemporáneas, la experiencia del fracaso puede ser identificada como un valor, un índice de autenticidad, en tanto presupone la inadecuación a expectativas convencionales. ${ }^{9}$ El título que Ribeyro eligió para la publicación de su diario alude al deseo de no lograr lo que supuestamente hay que perseguir - una obra acabada - para mantener activo el impulso de seguir buscando. La experimentación nacería de la duda y la insatisfacción respecto de lo logrado, no de la conformidad: el escepticismo como posición estética. En este sentido, otro título posible para el diario hubiese podido ser La tentación de lo inacabado. Como se trata de un autor de cuentos cortos, una forma cerrada y tradicional, la atracción por lo abierto e indeterminado tiene en Ribeyro una cualidad contradictoria, que habla de la complejidad de sus inclinaciones literarias y afectivas. Esa complejidad se despliega, en las páginas del diario, en una interrogación constante sobre si lo que está escribiendo tiene realmente valor, en un vaivén persistente entre satisfacción y descontento frente a la propia obra que las entradas registran, comentan y buscan equilibrar. También en el ámbito de la sociabilidad literaria, que es el de las luchas por la legitimación, algo de esta ambigüedad alimenta la tentación paradójica de que no se consume la busca de reconocimiento en la que, como cualquiera de sus pares, aunque con una discreción considerable, Ribeyro está comprometido. La entrada del 31 de diciembre de 1973, escrita al regreso de un viaje a Lima que resultó consagratorio (la adhesión de los colegas, la prensa y los lectores se manifestó ruidosamente), prueba que además de una forma conveniente de autofiguración, la incomodidad, incluso el rechazo frente al éxito, eran vivencias enraizadas en la intimidad del escritor, inclinaciones solidarias con los deseos de aislamiento y marginalidad que lo movían desde la adolescencia. Si "Solo pueden ser libres los solitarios" (Ribeyro), como sentencia el dicho 71 de Luder, incluso los intercambios que resultan beneficiosos tiende a debilitar esa fortaleza. Por eso el recuerdo de las entrevistas, las

9 Sobre la existencia de una "cultura del fracaso" como fundamento de ciertas experiencias estéticas contemporáneas, ver Yvette Sánchez y Roland Spiller. 
charlas públicas y las "comilonas" que se organizaron en Lima para celebrarlo, en las que participó activamente mientras transcurrían, queda registrado en el diario con tonos de amargura: "...moralmente, sensación de haber sido quizá en el fondo manipulado, puesto en el mercado como un producto cualquiera, envilecido por la publicidad y maculado por la propaganda" (396). Otro título posible para el diario hubiese podido ser La tentación de lo menor, si por "menor" entendemos la condición descentrada de obras y autores que operan en los márgenes de las instituciones culturales, activa pero discretamente, a los que un exceso de visibilidad no beneficiaría en nada y hasta podría desvirtuar. La identificación de Ribeyro con esta condición lateral, es fácil imaginarlo, resultaba menos confortable si intervenía la presunción de que los demás también se la atribuían, y que en el juicio de los otros lo "menor" se confundía con lo poco relevante. ${ }^{10}$

Una de las ocurrencias más interesantes de Prosas apátridas es la "Teoría del "error inicial"', según la cual en toda vida hay un mal paso originario e inadvertido, "un acto de negligencia, un falso razonamiento, la contracción de un tic o un vicio" (15), que ejerce sobre el futuro un efecto pernicioso secreto e inevitable. La repetición de conductas que dificultan la existencia, la predisposición a empantanarse en conflictos irresolubles o a quedar sometido a la presión de situaciones límites, no serían si no efectos de ese error cometido en un tiempo remoto, sustraído de la supervisión de la conciencia. Desde muy temprano, en las primeras entradas del diario, Ribeyro toma nota de las sensaciones de ineficacia y hastío que le revelan "el espectáculo de [una] vida equivocada" (6), la suya, que comienza a abandonar el curso previsto por las expectativas familiares, sin orientación definida, para hundirse irresponsable "en las arenas movedizas de la bohemia limeña" (La palabra del mundo 792). ${ }^{11}$ Menos por afán de aventura que por la apremiante necesidad

10 Ribeyro puede acordar con Paul Léautaud en que los autores de la "segunda repisa" de la biblioteca suelen ser más interesantes que las grandes figuras (530), y acomodar imaginariamente la propia obra sobre esos estantes alejados, si la especulación consigue poner entre paréntesis los valores dominantes y afirmarse en la elegancia de convicciones paradójicas, como las que promueve una ética de lo menor. Pero el gesto pierde vigor y se ensombrece cuando entra en diálogo con las expectativas de la Literatura como arte Mayor en sus propios términos: "14 de noviembre [de 1976] Escritor discreto. Tímido, laborioso, honesto, ejemplar, marginal, intimista, pulcro, lúcido: he allí algunos de los calificativos que me ha dado la crítica. Nadie me ha llamado nunca gran escritor. Porque seguramente no soy un gran escritor" (509).

11 La expresión pertenece a uno de los cuentos autobiográficos de madurez, "Ausente por tiempo indefinido" (incluido en Solo para fumadores, de 1987), que ironiza, sin neutralizar los aspectos sentimentales de la anécdota, el conflicto entre la voluntad de apartarse para crear con la escritura "un mundo paralelo, tan cierto e intenso como el otro, y quizás más hermoso y duradero" (800) y el impulso de abandonarse al llamado de la noche para salir al mundo de la bohemia. Las páginas del diario, las de la errancia durante la década del 50, pero 
de convertirse en un desconocido, ese primer desvío se amplifica enseguida en un derrotero azaroso de más de cinco años por algunas capitales europeas. En París, hacia 1953, el error originario se manifiesta en la imposibilidad de habitar el presente: "Hay algo que anda mal en mí [únicamente goza de los recuerdos y los proyectos] y que me hace inepto para la felicidad" (22). Dos años más tarde, en Madrid, sus huellas se transparentan en la "fría pasión por el desorden" (6o), la única constante que puede advertir en su naturaleza, la razón de las imprevisiones y la tendencia irrefrenable al dispendio que reducen periódicamente su condición de becario a la de pordiosero. En Amberes, pasados otros dos años, el diarista especula sobre los comienzos de su "incapacidad para la vida social" (138) y tiene que remontarse, espantado, hasta algunas vivencias infantiles: el sentimiento de incomodidad que sufre en compañía de sus semejantes y lo inclina a la soledad y el silencio es tan antiguo como su uso de razón. Hasta que en 1961 entra como redactor de la agencia France-Presse y queda establecido en París (después del primer día siente unas ganas violentas de abandonar todo), el diario es la bitácora de una continua fuga hacia adelante, para huir de un futuro conveniente de abogado y profesor universitario a punto de consumarse, que se realiza bajo el signo exorbitante del gasto sin reservas: liquidación frenética de cualquier recurso económico (en una sola noche gasta el monto completo de un mes de beca; en tres o cuatro meses, lo que le tocó de la venta de unos departamentos que la familia heredó del padre) $;{ }^{12}$ desgaste indulgente de los recursos afectivos (los únicos amores con los que se compromete son los imposibles: C. en París, Mimí en Amberes) $;^{13}$ deterioro pautado de la salud, por el

también algunas de la temprana madurez, despliegan reflexivamente distintos aspectos de este conflicto: la tensión entre preservarse y perderse en la extenuación y el dispendio, entre la necesidad del soliloquio y el gusto por la conversación proliferante, entre el placer de trabajar y el goce de diferir. La entrada del 5 de marzo de 1958 (reproducida en el fragmento 67 de Prosas apátridas) sobre su "faceta de animal nocturno" (174), enigmática e inquietante, debe leerse en el contexto de estas tensiones, que pudieron atemperarse con el paso de los años y el establecimiento de la vida familiar, pero que jamás desaparecieron por completo.

12 Cuando la inclinación al dispendio haga presa de las hecatombes el sueldo de la Agencia ("Todo dinero que llega a mis manos se quema"), en la entrada del 12 de setiembre de 1969, Ribeyro ensayará un alegato autoindulgente de su "prodigalidad" con tal elegancia que casi resulta convincente: "Los pródigos, ¿ ¿no serán en el fondo optimistas? Confían en el mañana o no les importa el mañana. Saben, en realidad, que todo podrá arreglarse. Los avaros son cobardes" (356). Como la intimidad es el reino de lo ambiguo, en entradas posteriores, dictadas por el sentido común, se amonesta ante la posibilidad de que la mujer y el hijo sólo hereden deudas en caso de que se precipite su muerte.

13 Más que la posibilidad de amar buscaba la ocasión de ser amado, por eso ironizaba sobre el influjo que la lectura del Adolfo de Benjamin Constant había tenido en su temperamento (31). Si el tópico no resultara tan tedioso, se podrían escribir algunas notas sobre la misoginia de 
hábito de la noche, el alcohol, los cigarrillos y la literatura (el arte sería otra forma de autodestrucción porque su práctica exige silenciosamente la ruptura de cualquier vínculo con el mundo de las necesidades).

La lectura en clave benjaminiana de la primera década de La tentación del fracaso, la de los años de la bohemia, muestra cómo "la persona dramática que los diarios crean se configura sobre la base de tropos de la literatura del siglo XIX" (Esparza 118) que remiten directamente a la poesía de Baudelaire: la experiencia del tedio (ennui) como punto de vista de una subjetividad excepcional, marcada por lo sublime; la mezcla de fascinación y rechazo con la que el solitario circula a través de la multitud; la sensación de desamparo y melancolía que sufre el artista, mientras afirma su superioridad espiritual, porque el burgués domina el mundo de las actividades productivas, mundo inapelable en el que él se figura como un incapaz o un retrasado que todavía no aprendió a vivir. ${ }^{14}$ "Mayo [de 1973]. Lo que no he aprendido en mis cuarenta y cuatro años de vida ni aprenderé nunca es a vivir. Saber vivir: frase banal, hecho capital" (388). La fecha delata la persistencia, todavía en la madurez, de la figura del inadaptado a los requerimientos de una existencia estable: "De mis diez años en la AFP sólo saqué deudas y una enfermedad, mientras la mayoría de mis compañeros compraron casa, auto, muebles, viajes y queridas. Lo mismo en la Embajada y en la Unesco... ¿ Por qué?" (Ídem). La teoría del error originario permite apreciar el lado más oscuro y activo de la incapacidad para sacar partido de las situaciones favorables: la resistencia a hacerlo, la necesidad inexplicable y perentoria de vivir situaciones límites. Observada de cerca, con la proximidad minuciosa a la que accedemos siguiendo los gestos introspectivos del diarista, esa compulsión revela su costado menos previsible, el conservador. La práctica del gasto sin reservas, tan autodestructiva como excitante, no se sostiene sin la provisión continua de recursos sacrificables. Ribeyro se las arreglaba bien para conseguirlos (no sólo llegó a diplomático sino que pudo conservar el puesto después de la caída del Gobierno que lo había nombrado), ${ }^{15}$ no sabía vivir pero sabía cómo administrar las agonías de la supervivencia para garantizarse la repetición.

Ribeyro en su diario, escandalosamente convencional (ver por ejemplo la entrada del 3 de abril de 1958, sobre las mujeres bellas como objetos de uso (178), o la del 21 de agosto de 1974 (420), una variación trasnochada del mismo argumento).

14 La identificación de la figura del diarista con una sensibilidad decimonónica desborda ampliamente la primera década de La tentación del fracaso. Como acierta Juan Gabriel Vázquez, la habitación que el escritor peruano ocupó en sus años de bohemia europea es "la que ocuparía el resto de su vida: el siglo XIX. De alguna manera, [en aquellos años de aprendizaje] ya era lo que sería toda su vida: un anacronismo" (Vázquez 12).

15 Ribeyro accedió al cargo de Agregado cultural de la Embajada de Perú en París y al de Delegado adjunto ante la UNESCO gracias a su amistad con el General Juan Velasco Alvarado. 
La teoría del error originario nunca funciona como recurso expiatorio: aunque se podría decir que no estuvo presente cuando contrajo de por vida una inclinación perniciosa, nada exime al vicioso de la responsabilidad frente a las pequeñas catástrofes que ocasionan sus elecciones arcaicas. Los alcances de esta teoría son éticos, no morales, ${ }^{16} \mathrm{y}$ su eficacia es novelesca cuando interviene entre los presupuestos que explicarían los infortunios o las necedades de una vida de artista. La intimidad con el sinsentido de lo que se repite a pura pérdida transforma al sujeto del error en un personaje de novela (una especie de antibildungsroman). Así Julio Ramón Ribeyro, en una entrada de su diario de febrero de 1967:

Hasta ahora me considero como un hombre que ha sido aplazado en todas las pruebas de la vida. Me acerco a los 40 años sin gloria, sin dinero, sin salud, sin influencias, sin tranquilidad, sin perspectivas. (...) ¿Qué hago lejos de mi país, en una ciudad donde tengo sólo dos o tres amigos, obligando a mi mujer a una vida de encierro, en dos piezas con goteras y cucarachas, desempeñando un trabajo mecánico y subalterno [como redactor de la AFP]? ¿Quién me ha exilado y por qué? ¿Qué busco? ¿Qué aguardo? (329).

La respuesta a la primera pregunta es simple, el diarista la conoce bien aunque juegue a ignorarla para acentuar el dramatismo de la situación: se fue quedando porque descubrió en París un "maravilloso reducto del individualismo" (76), una ciudad ideal, por lo refractaria, para perderse entre la multitud sin riesgos de asimilación. ${ }^{17}$ Las otras preguntas aluden al misterio de fuerzas y designios inescrutables que convierten el personaje del exilado en una figura trágica: sujeto al dominio de una presencia desconocida ("¿Quién...?"), se siente fuera hasta de sí mismo, no sabe ni qué busca ni qué puede esperar.

Cuando Velasco fue depuesto por el general Morales Bermúdez en 1975, Ribeyro no presentó la esperable renuncia y pudo conservar los cargos. En la entrada del 9 de diciembre de ese año, con la indulgencia que es de rigor en las confesiones, reconoce la falta de lealtad.

16 Porque le asigna a la conciencia un rol secundario en la toma de las decisiones fundamentales, el de un testigo perplejo que llega tarde.

17 La relación de Ribeyro con París elude la previsible celebración del cosmopolitismo que era de rigor entre sus pares (basta pensar en Rayuela) porque está signada por el inconformismo de una vocación extraterritorial: en las páginas del diario fechadas en la capital francesa, "persiste la sensación de no encontrarse a gusto en ningún lugar y de ser un marginal aun dentro del grupo de escritores latinoamericanos que residen en Europa" (Esparza 115), sensación que el diarista se cuida bien de preservar. En un ensayo temprano, para ejercitar las dotes de moralista irónico, Ribeyro ensayó una clasificación incisiva de los "Peruanos en París", en la que ya se perfila indirectamente la singularidad de su condición de paria irredimible (La caza sutil 49-54). 
La escritura de la intimidad mantiene con los efectos del error originario dos tipos de relaciones, según cuál sea el interés de la voluntad que prevalece: por el lado del narcisismo autocomplaciente, se regodea en el comentario de las inclinaciones que dificultan la vida porque las toma por signos de una excepcionalidad ruinosa pero fascinante; por otro lado, más activo, trabaja con las armas de la imaginación y el análisis para resguardar la identidad del diarista de la confusión y el extravío, para dejar algo a salvo de la dispersión y la negligencia. Además del escepticismo, que lo lleva a no tomarse nada demasiado en serio, a veces ni siquiera a sí mismo, Ribeyro cuenta con otro recurso extraordinario para sostener el trabajo que realiza en algunas entradas del diario cuando intenta equilibrarse en momentos difíciles: su "fuerza moral", un don que lo acompaña desde la juventud ${ }^{18}$ y que se manifiesta discretamente como un optimismo tenaz, la creencia en que siempre hay algo productivo para hacer, por poco que sea, o la convicción en que la voluntad siempre tiene cierto poder para contrarrestar cualquier forma de amenaza. La potencia de esta última convicción, como causa y efecto de la escritura del diario, se intensifica radicalmente cuando le toca confrontarse, no con las consabidas dificultades para vivir sino con la posibilidad inquietante de que la vida se extinga por la propagación de un cáncer de esófago.

Desde la primera entrada de 1973, La tentación del fracaso se convierte en el diario de un convaleciente ejemplar, que repite en la intimidad de las notaciones la misma política de discreción y estoicismo que practica en la vida cotidiana con quienes lo rodean, para no afligirlos ni incomodarlos y para cuidar de sí mismo. La resistencia a dramatizar, incluso en los momentos más difíciles, los de las internaciones y los postoperatorios, tiene que ver en principio con el interés por no perder la compostura ni abandonarse a la desesperación; en un nivel más profundo, con la voluntad de bloquear la afluencia de pensamientos negativos que amedrentan, contrarrestar el debilitamiento y generar condiciones para que la "fuerza moral" pueda ejercer alguna acción reparadora. La entrada del 18 de julio 1977, que aquí citamos in extenso, expone reflexivamente la creencia en el poder sanador de ciertos movimientos de la conciencia que actuarían benéficamente sobre una zona imaginaria en la que lo biológico y lo espiritual se cruzan e interactúan:

(...) Una enfermedad es un hecho real, una enfermedad como la mía, algo que se da a nivel celular y que puede verificar el microscopio, la radiografía, la biopsia, etc. Pero esa enfermedad es un proceso químico, aparentemente inaccesible a nuestro control. Ese proceso sigue su marcha mientras seguimos

18 Ver la entrada del 22 de noviembre de 1973 (394). 
viviendo, hasta hacer la vida imposible. El asunto está en poder localizar el punto de convergencia, en el cual el proceso biológico se cruza con otros factores que pueden influir sobre él y determinar su curso. Es la zona del milagro. El pensamiento no es una emanación imponderable, un soplo, algo contiene, conduce y ordena. Dirigirlo poderosamente sobre el punto vulnerable y actuar sobre lo infinitamente pequeño y destructor. Ensayarlo, al menos. $\mathrm{Y}$ por ello mismo mostrarse confiado, en la medida en que creemos contar todavía con un arma (558).

La escritura del diario como práctica de supervivencia - en esto reside su más alto valor ético - cumple funciones de contención, ya que en sus páginas quedan registrados, con ánimo catártico, los padecimientos y las agonías que Ribeyro prefiere silenciar en la conversación con su mujer y los amigos, y también otras más ambiciosas y esotéricas, de programación y control de las improbables tentativas para reducir la potencia aniquiladora de la enfermedad a través de la intervención conjetural del pensamiento sobre las células comprometidas.

Los estudiosos del género conocen bien la "Deliberación" en la que Roland Barthes (1986) expuso sus reservas sobre la conveniencia estética y espiritual de llevar un diario íntimo, y saben que en el caso de los escritores esa deliberación se realiza, por lo general, en el interior mismo del diario, imprimiéndole a la sucesión de las entradas un curso espiralado que despliega la desconfianza del diarista sobre el poder del lenguaje, dada su tendencia a lo general y lo estereotipado, para ahondar en el dominio de las afecciones íntimas y satisfacer los anhelos de sinceridad. Cuando en la introducción a La tentación del fracaso Ribeyro se jacta de inaugurar en el medio latinoamericano una expresión literaria nunca utilizada, "el diario del escritor" (2), diferente, no sólo por razones temáticas, de los diarios de exploradores, viajeros o políticos, piensa en un diario que funciona como cuaderno de ejercicios estilísticos y "laboratorio" de lo que procesarán luego las ficciones y los ensayos, que registra y desmenuza los vínculos que el escritor establece en diferentes momentos con el proceso de la creación (sobre todo en los momentos de "sequía", dominados por la imposibilidad de escribir), un diario que se presta para el ensayo, a vuelo de pluma, de comentarios críticos sobre lecturas del momento y para la crónica fugaz de algún episodio memorable de la vida literaria. Desde el punto de vista de la deliberación que inquieta sus fundamentos estéticos y morales, el de los escritores es también un diario que plantea el encuentro de notación y vida desde una perspectiva literaria, y desde esa perspectiva se interroga por el valor y la eficacia del hábito (¿disciplina, pasión, manía?) de anotar algo en cada jornada. Aunque por lo general tiendan a situarlo sobre 
el borde externo de los márgenes que delimitan su actividad (no será el caso de Ribeyro cuando se convierta en editor de sus cuadernos y proyecte publicarlos), la práctica del diario personal plantea a los escritores problemas específicos de técnica literaria: la búsqueda de un tono y un estilo justo ("apretado, expresivo" (210)), ligada a la conciencia que han adquirido sobre las potencias y las limitaciones del lenguaje cuando se propone capturar los matices de un fragmento de vida circunstancial e irrepetible. Al referirnos a la perspectiva literaria que sitúa la deliberación sobre el valor y la eficacia de la práctica del diario, pensamos a la vez en exigencias institucionales determinadas históricamente (¿qué significa encarnar la figura del diarista, un clásico decimonónico, en la segunda mitad del siglo XX, cuando hasta el más ingenuo de los escritores está advertido sobre las imposturas que moviliza el recurso a la introspección?) y en los requerimientos del deseo de literatura que liga secretamente al escritor con su obra, deseo de un encuentro inmediato entre escritura y vida, más acá del sentido y los valores que impone el gregarismo de los signos. ${ }^{19}$

Todas las reservas morales que la práctica del diario íntimo despierta en los escritores modernos ya fueron enunciadas, a mediados del siglo XIX, en el Diario de Henri-Fréderic Amiel, el clásico del género (Ribeyro lo descubrió a los catorce años en la biblioteca paterna, en una edición en dos volúmenes, y esa lectura despertó en él la necesidad de emularlo). El ejercicio continuo de la introspección ayuda a esquivar la vida más que a realizarla plenamente, sustituye la acción por la descripción y consume las fuerzas necesarias para la escritura de la verdadera obra; no es más que un simulacro de actividad intelectual y casi siempre tiende a la autocomplacencia. ${ }_{\mathrm{C}}$ Por qué perseverar entonces en la rutina de anotar en cada jornada alguna de las impresiones o los pensamientos que capturaron la atención? También debemos a Amiel la enunciación de las respuestas proverbiales: además de servir para la ejercitación de las destrezas retóricas ("ablandar la mano"), la práctica del apunte circunstancial agudiza la capacidad de análisis y, si sabe fijar lo esencial, puede contribuir al restablecimiento de la integridad espiritual y el equilibrio de la conciencia del diarista.

En la introducción, sobre las huellas de Amiel, Ribeyro define el diario íntimo como "una ocupación peligrosa" (2), que puede obstruir la comunicación con los otros en beneficio de un soliloquio estéril y suplantar el impulso de escribir la obra por la especulación obsesiva sobre los problemas y perplejidades que

19 Para una caracterización del diario de escritor y el proceso de deliberación que lo atraviesa y lo constituye, ver "Vida y obra. Roland Barthes y la escritura del Diario" (en Giordano 91-108). 
impiden realizarla. Aunque trató de sortearlas durante su prolongada experiencia como diarista, reconoce que por épocas sucumbió a estas dificultades (tal vez porque encontró en ellas otros modos de ceder a la tentación del fracaso). En una digresión más ligera, también en la estela del maestro ginebrino, exalta las virtudes del diario como compañía del célibe y complemento de la actividad literaria, a la que puede servir de estímulo y orientación. La identificación de Ribeyro con Amiel, con los hallazgos de su estilo geométrico, pero también con las arideces de su misantropía, es tan fuerte, sobre todo en los cuadernos de la primera década, que le despierta deseos de imitación pero también inquietud y una saludable necesidad de distanciamiento. De esa incomodidad es testimonio la entrada del 23 de noviembre de 1955, un año signado por las crisis espirituales, en la que Ribeyro se encarniza con la retórica intimista de su precursor por considerarla un caso típico de "análisis a la segunda potencia" (La tentación del fracaso 91), análisis que se devora a sí mismo por falta de un objeto sobre el cual aplicarse. Lo que hace tan particular a La tentación del fracaso es la intensidad y la variedad de matices del proceso de deliberación y cuestionamiento que la recorre de punta a punta, un movimiento de vaivén obstinado que tiene una de sus manifestaciones más patentes en las oscilaciones del juicio que valora la figura de Amiel: en ocasiones es un modelo estimulante del éthos intimista (y un "monumento único de la lengua francesa", como Montaigne y Pascal), ${ }^{20}$ en otras, el nombre de un síndrome morboso, la imagen -en la que es difícil no reconocerse- del diarista como enfermo de autocomplacencia y esterilidad. Además del vaivén axiológico, hay otros dos rasgos que singularizan la deliberación sobre los límites y las posibilidades del género que atraviesa el diario de Ribeyro: la insistencia, que reabre el proceso continuamente, $y$ en ocasiones la severidad.

La presencia tan marcada de estos dos rasgos se explica en principio por la condición de erudito que Ribeyro conquistó gracias a una afición propia de coleccionista: la lectura continua de diarios íntimos de cualquier especie (llegó a atesorar más de un centenar) lo convirtió tempranamente en un especialista en el género advertido sobre las posibilidades, pero también sobre las trampas y los espejismos, de la introspección y el registro de lo cotidiano. La reflexión que duplica el acto de la notación para atribuirle un valor casi siempre negativo (es posible que el juicio moral tranquilizase la concia del diarista, pero rara vez decidió la interrupción de la práctica) aparece inscripta ya en una entrada de 1950, la del 5 de diciembre: nada respalda la "locura" de haber comenzado a llevar

20 El énfasis pertenece a Maurice Chapelang, y Ribeyro lo cita en "En torno a los diarios íntimos" (La caza sutil 12). 
un diario que no es más que "una colección de hechos nimios, pésimamente redactados, donde la insipidez de mi vida está pintada con la elocuencia de un picapedrero" (9). Al año siguiente, en la entrada del 20 de mayo, anota los deseos de abandonar el diario y volcarse al mundo (deseos impostados, como todo lo que manifiesta retraimientos de índole puramente moral) porque su "yo es un motivo decepcionante de observación" (13). A comienzos de 1953, ya en París, después de ocho meses de interrupción involuntaria (los diarios no recogen la exaltación de los días felices), la deliberación explora la otra vertiente, la del reconocimiento de las virtudes espirituales y prácticas del intimismo: retoma el diario, no para ensimismarse, sino para "... anotar algunas impresiones fugaces que más tarde placería recordar, estimular un poco mi reflexión sobre ciertos tópicos que el pensamiento meramente pensado no alcanza a sistematizar, hacer un poco de ejercicio de estilo y sobre todo reunir materias - frases, descripciones, ideas aprovechables más tarde en mis artículos o creaciones literarias" (21). La reconciliación con el costado positivo del legado de Amiel es contemporánea de la escritura de "Entorno a los diarios íntimos", otro notable ensayo de juventud (notable por la madurez del estilo expositivo) destinado a informar a un público amplio sobre los orígenes y las características del género, sus relaciones estrechas con la correspondencia, las razones de su actualidad en el medio europeo y de su casi inexistencia en el latinoamericano. ${ }^{21}$

El momento más extraordinario de la deliberación tiene lugar en la entrada del 29 de enero de 1954. En seis párrafos que comienzan con la frase "Todo diario íntimo...", Ribeyro elabora una teoría del género que excede ampliamente los alcances de cualquier digresión circunstancial. Cada párrafo es un modelo de economía sintáctica y precisión argumentativa en el que se decanta un saber, enraizado en la experiencia personal, sobre los compromisos éticos del diarista con una práctica que tiende a disimular sus rarezas y ambigüedades bajo la fachada de un ejercicio provechoso al que se le atribuyen funciones convencionales. "Todo diario íntimo surge de un agudo sentimiento de culpa" (29) cuyo peso se aligera cuando se confían las causas al cuaderno que oficia de confesor implacable. Pero "Todo diario íntimo es también un prodigio de hipocresía" (29), porque la inclinación a desconocer las auténticas razones que nos mueven cuando fallamos son más poderosa que la más honesta voluntad de confesión. Por eso hay que aprender a leer los diarios "entre líneas", para adivinar lo que la sinceridad y el

21 Antes de ser recogido en La caza sutil, este ensayo fue publicado originalmente en el Suplemento Dominical de El Comercio (Lima, 30 de enero de 1955), del que Ribeyro era asiduo colaborador por aquellos años. 
espíritu de constricción disimulan y relegan al olvido casi imperceptiblemente. "Todo diario íntimo nace de un profundo sentimiento de soledad" (29), que comenta y profundiza, casi como si se tratara de un motivo de orgullo, aunque no falten los lamentos. "Todo diario íntimo es un síntoma de debilidad de carácter" (29), debilidad que el registro de las frustraciones no sólo no remedia sino que fortifica, porque bajo la presión del estilo la escritura transmuta lo doloroso en interesante. "En todo diario íntimo hay un problema capital planteado que jamás se resuelve y cuya no solución es precisamente lo que permite la existencia del diario. El resolverlo, trae consigo su liquidación" (29). ¿Cuál pudo ser el problema irresoluble que permitió la prosecución del diario de Ribeyro por más de cuatro décadas (si contamos los cuadernos inéditos)? La respuesta es difícil, por tratarse de alguien que rehuía el éxito, la centralidad y el ejercicio del poder en cualquiera de sus manifestaciones. Tal vez haya sido la imposición de habitar un mundo demasiado real y contemporáneo. "Pariente pobre y tardío de Constant, de Stendhal" (221-22), prefería vivir a destiempo y un poco distanciado del curso de los acontecimientos, incluso de los estrictamente privados, absorbido por las pasiones eminentemente literarias de lo anacrónico y lo imaginario. La última sentencia es la más enigmática, "Todo diario íntimo se escribe desde la perspectiva temporal de la muerte" (30), y aunque carece de desarrollo, es probable que remita al presupuesto de que los papeles personales de un escritor sólo se convierten en obra literaria cuando se los lee póstumamente.

Ribeyro podía abrir su cuaderno a media noche para descalificar la práctica del diario íntimo por disparatada, inútil y casi nauseabunda, sin advertir la paradoja del gesto. ${ }^{22}$ Con el paso de los años, la tensión entre el deseo de anotar siempre algo más, extremando la curiosidad o la sutileza, y la creencia de que esa práctica era perniciosa porque lo apartaba del mundo, como si realmente desease ir a su encuentro, no hizo más que amplificarse. Por un lado, desde que comienza a gravitar el proyecto de la futura publicación (digamos, a principios de 1960, cuando advierte que el diario forma parte de la obra), "las entradas comienzan a ser progresivamente la obra de un estilista consciente" (Márquez 315) de los efectos literarios de cada notación. La búsqueda de un estilo intimista justo se profundiza sobre todo en los últimos años, con el aumento considerable de la frecuencia de las entradas y la ampliación del registro temático a partir de la experiencia de la enfermedad. Por otro lado, la crítica moral a las limitaciones del género se sostiene a la par casi sin variaciones, y muy tardíamente estalla, con

22 Ver la entrada del 10 de mayo de 1956 (105). 
extrema virulencia, nada menos que contra los diarios de Léautaud, un clásico contemporáneo:

22 de marzo [de 1977]

...me doy cuenta del carácter estéril, irritante de este tipo de obras, refugio de escritores fascinados por su propia persona y que no pudieron nunca emanciparse de la autocontemplación para acceder a la esfera verdaderamente creativa y superior de la impersonalidad. (...) El gran escritor no es el que reseña verídica, detallada y penetrantemente su existir, sino el que se convierte en el filtro, en la trama a través de la cual pasa la realidad y se transfigura (520-521).

La crítica, en sus términos, es justa, pero tal vez no sea en los términos de la impersonalidad propia de la experiencia literaria que haya que juzgar los aciertos estéticos de un diario de escritor, sino en otros menos exigentes, pero más afines con los encantos del género, los de la invención del personaje del diarista como criatura imaginaria. Los diarios de escritores que leemos con fruición, como seguramente Ribeyro leía los de Léautaud antes de que lo asaltase la inquietud sobre su propio narcisismo, son los que presentan al diarista como una figura rica en matices, contradictoria, incluso ambigua, por aquello en lo que se transforma su vida cuando decide hacerla pasar por las páginas de un diario. No disponemos de mejor ejemplo para ilustrar esta hipótesis que la entrada de La tentación del fracaso que sigue inmediatamente a la que acabamos de citar, la del 7 de abril. La notación se detiene en el registro del desorden y el abandono extremos que se apoderan del viejo departamento que habita el escritor sobre la Plaza Falguière, cuando la esposa y el hijo se ausentan circunstancialmente. Los ceniceros desbordan de colillas y se multiplican por todas las habitaciones; para salir del cuarto hay que sortear montañas de ropa sucia; la dispersión de libros y papeles es incesante, y en la cocina una capa de grasa cubre e inutiliza la vajilla y los cacharros. Para colmo, cortaron el gas por falta de pago y hay que andar con el sobretodo puesto. En el remate, la notación explicita un deslizamiento hacia la imaginación narrativa que está implícito en otras tantas - las mejores - páginas del diario: "Rechacé invitaciones para cenar, para ir al café, al cine, sólo por no tener que afeitarme. Decididamente me voy convirtiendo en el personaje de uno de mis cuentos" (521). 


\section{Obras citadas}

Barthes, Roland. "Deliberación". Lo obvio y lo obtuso. Imágenes, gestos, voces.

Trad. Carlos Fernández Medrano. Barcelona: Paidós, 1986. 365-380.

Esparza, Cecilia. "Cap. IV.Julio Ramón Ribeyro: El diario como acompañante del artista”. El Perú en la memoria. Sujeto y Nación en la escritura autobiográfica. Lima: Red Para el Desarrollo de las Ciencias Sociales en el Perú, 2006. 97-135.

Giordano, Alberto. La contraseña de los solitarios. Diarios de escritores. Rosario: Beatriz Viterbo, 2012.

Márquez, Ismael P. "Una poética de la narrativa en los diarios de Julio Ramón Ribeyro". Asedios a fulio Ramón Ribeyro. Eds. Ismael P. Márquez y César Ferreyra. Lima: PUCP, 1996. 311-320.

Ribeyro, Julio Ramón. La caza sutil (Ensayos y artículos de crítica literaria). Lima: Milla Batres, 1976.

—. Dichos de Luder. Lima: Jaime Campodónico, 1989.

-. La tentación del fracaso. Diario personal (1950-1978). Prólogos de Ramón Chao y Santiago Gamboa. Barcelona: Seix Barral, 2003.

-.Prosas apátridas (completas). Lima: Seix Barral, 2006.

-. La palabra del mundo. Barcelona: Seix Barral, 2010.

Sánchez, Yvette y Spiller, Roland (eds.). Poéticas del fracaso. Tubingen: Gunter Narr Verlang, 2009.

Vázquez, Juan Gabriel. "Diario de un diario. Tras los pasos de Julio Ramón Ribeyro". Quimera 279, 2007. 12-17.

Yáñez, Agustín. "Moralistas franceses". Memoria del Colegio Nacional. Tomo 4. 1961. 113-141.

Zanetti, Susana. "Diario de un escritor: La tentación del fracaso, de Julio Ramón Ribeyro". Iberoamericana julio de 2006. 63-77. 